\title{
Stressed out symbiotes: hypotheses for the influence of abiotic stress on arbuscular mycorrhizal fungi
}

\author{
Niall S. Millar ${ }^{1} \cdot$ Alison E. Bennett $^{2}$
}

Received: 21 January 2016 / Accepted: 9 June 2016 / Published online: 27 June 2016

(C) The Author(s) 2016. This article is published with open access at Springerlink.com

\begin{abstract}
Abiotic stress is a widespread threat to both plant and soil communities. Arbuscular mycorrhizal (AM) fungi can alleviate effects of abiotic stress by improving host plant stress tolerance, but the direct effects of abiotic stress on AM fungi are less well understood. We propose two hypotheses predicting how AM fungi will respond to abiotic stress. The stress exclusion hypothesis predicts that AM fungal abundance and diversity will decrease with persistent abiotic stress. The mycorrhizal stress adaptation hypothesis predicts that AM fungi will evolve in response to abiotic stress to maintain their fitness. We conclude that abiotic stress can have effects on AM fungi independent of the effects on the host plant. AM fungal communities
\end{abstract}

Communicated by Maria J. Pozo.

This paper makes an important to our understanding of the influence of abiotic stress on the ecology and evolution of one the most important interactions in nature: that between AM fungi and plants. We highlight the direct effects of abiotic stress on AM fungi, which we feel have been previously overlooked. We develop two testable hypotheses that detail how the community composition of AM fungi will be effected by abiotic stress in the short term, and how AM fungi will be selected for improved abiotic stress tolerance following repeated exposure to abiotic stress.

Electronic supplementary material The online version of this article (doi:10.1007/s00442-016-3673-7) contains supplementary material, which is available to authorized users.

Alison E. Bennett

Alison.Bennett@hutton.ac.uk

1 School of Life Sciences, University of Dundee, Dundee DD1 $4 \mathrm{HN}, \mathrm{UK}$

2 Ecological Sciences, James Hutton Institute, Errol Road, Invergowrie, Dundee DD2 5DA, UK will change in composition in response to abiotic stress, which may mean the loss of important individual species. This could alter feedbacks to the plant community and beyond. AM fungi will adapt to abiotic stress independent of their host plant. The adaptation of AM fungi to abiotic stress should allow the maintenance of the plant-AM fungal mutualism in the face of changing climates.

Keywords Soil · Adaptation · Community · Symbiosis · Climate change

\section{Introduction}

Abiotic stress is widespread. While abiotic stress is common in all environments, its effects are best documented in agricultural systems where abiotic stresses can cause losses in yield of food crops of up to $70 \%$ (Mantri et al. 2011). Drought (Pardo 2010; Cramer et al. 2011), temperature (Weis and Berry 1988), salinity (Munns and Tester 2008), pH (Yokota and Ojima 1995; Koyama et al. 2001; Hinsinger et al. 2003), and nutrient deficiency or excess all negatively impact plant fitness. Arbuscular mycorrhizal (AM) fungi can often help alleviate the negative consequences of these stresses.

The arbuscular mycorrhizal symbiosis is an important relationship formed between the members of the phylum Glomeromycota and $~ 80 \%$ of all land plants (Smith and Read 2008). AM fungi are obligate symbionts that colonise plant roots. The fungi gain carbohydrates from the plant host, while the fungi improve plant nutrient and water uptake. The benefits to plant partners can vary depending on the AM fungal species, plant species, and abiotic context (Hoeksema et al. 2010). AM fungal community composition and diversity are influenced by plant community 
composition and diversity (Johnson et al. 2004; Hausmann and Hawkes 2009; De Deyn et al. 2011; Koch et al. 2012; López-García et al. 2014; Chagnon et al. 2015; Reininger et al. 2015), biotic stress (Eom et al. 2001; Gehring and Bennett 2009), and abiotic factors (Johnson et al. 1992; Zobel and Öpik 2014; Antoninka et al. 2015; Borriello et al. 2015; Klabi et al. 2015). In addition, these factors often interact to influence AM fungal community structure and diversity (e.g., Johnson et al. 1992; Klabi et al. 2015). Despite our awareness of the influence of these factors on AM fungal community structure and diversity, predominantly only the evolutionary influence of plant community composition on AM fungi has been explored (Kiers and Van Der Heijden 2006; Wyatt et al. 2014; but see Behm and Kiers 2014; Johnson 1993).

The AM symbiosis has been shown to reduce the negative effects of abiotic stresses. In this study, we define abiotic stress as a shift in any non-living factor within the environment away from the optimal condition or away from the condition to which most organisms in that environment have become adapted. While abiotic stress is context dependent, there are a number of examples demonstrating the impact of AM fungi in improving abiotic stress tolerance in plants. AM fungi improve plant fitness during drought (Smith and Read 2008) possibly due to the increased surface area for water absorption provided by AM hyphae (Auge 2001), increased access to small soil pores (Smith and Read 2008), or improved apoplastic water flow (Bárzana et al. 2012). Improved phosphorus nutrition is a common benefit of the AM symbiosis, and particularly during drought conditions, AM fungi improve $\mathrm{P}$ uptake from dry soil (Neumann and George 2004). AM fungalimproved salinity tolerance (Al-Karaki 2000; Evelin et al. 2009) has been hypothesised to be due to improved P nutrition, improved ion homeostasis, maintaining photochemical capacity, and higher activity of antioxidant enzymes (Hajiboland et al. 2009). Heavy metal toxicity for plants can be reduced by AM fungi, through hyphal 'metal binding' which reduces the bioavailability of elements, such as $\mathrm{Cu}, \mathrm{Pb}, \mathrm{Co}, \mathrm{Cd}$, and $\mathrm{Zn}$ (Audet and Charest 2007). AM fungi may also be more tolerant than plant roots of high temperatures (Bunn et al. 2009), and induce higher enzymatic activity and secondary metabolite content in plants (Chen et al. 2013) leading to greater cold tolerance in host plants. As a result, AM fungi can clearly benefit host plants exposed to abiotic stress.

As mentioned above, less attention has been paid to the direct selective effects of abiotic stress on AM fungi themselves, independent from the effect on their host. Abiotic stress also impacts host plants, and therefore, abiotic stress will indirectly influence AM fungi via host plants, although this influence is likely to follow patterns similar to those identified for the influence of plants on AM fungi under ambient conditions (Kiers and Van Der Heijden 2006; Wyatt et al. 2014). As a result, in this study, we address the possible direct effects of abiotic stress on the fitness, diversity, evolution, community composition, and symbiotic functioning of AM fungi. Studying the effects of abiotic stress on AM fungi separately from plants will help to provide a better understanding of the strengths and weaknesses of their ubiquitous relationship.

Like in all organisms, environmental variation causes selection for different traits in AM fungi. This leads to individuals differing in their symbiotic function based on the contrasting climates or soil conditions of the areas they originated from (Mena-Violante et al. 2006; Antunes et al. 2011; Sochacki et al. 2013). It has been suggested that local adaptation to varying environmental conditions produce more important differences in AM fungi than the basic functional differences between coexisting AM fungal taxa (Sanders 2002). Adaptation to environmental conditions can even be seen in highly localised areas, for example, within a natural $\mathrm{CO}_{2}$ spring, where hypoxia has driven the selection of AM fungal species capable of surviving high concentrations of $\mathrm{CO}_{2}$ resulting in AM fungi with reduced extra-radical mycelia and enhanced uptake of oxygen from the roots of the plant (Maček et al. 2011). Similarly, the ability of three AM fungal phylotypes from Yellowstone National Park to survive in geothermal soils is likely due to tolerance of low pH conditions (Appoloni et al. 2008). Evolutionary responses to abiotic stress not only improve the ability of an AM fungus to survive, but may also benefit the host plants exposed to the same stress (Mena-Violante et al. 2006; Sochacki et al. 2013). This may not be equally true for all stresses, however. For example, increased nutrient loads have been suggested to reduce the benefit AM fungi deliver to host plants (Johnson 1993; Antunes et al. 2012). Only in extreme cases are nutrients present in such excess as to directly damage plants (Scheirs and De Bruyn 2004), but many changes in nutrient availability away from the level plants and fungi are adapted to can be considered an abiotic stress, and, in addition, nutrient availability can undermine the benefits that plants receive from the mycorrhizal symbiosis (Johnson 1993). The potential for AM fungi to adapt to novel conditions may be a particularly important characteristic for an organism with limited dispersal capabilities.

The benefits provided to plants by AM fungi will become even more important, due to increasing abiotic stresses caused by climate change (Hanson and Weltzin 2000; Compant et al. 2010). This is demonstrated by the knock-on effects on plant communities that can occur when AM fungal diversity or community composition is changed (van der Heijden et al. 1998; Antoninka et al. 2009; Sun et al. 2013). Knock-on effects occur if plants differ in their response to specific AM fungal species, or if they have 
varying levels of general dependence on the symbiosis. In this case, a change in AM fungal community composition could, for example, make a species of plant dependent on the AM symbiosis (or a particular AM fungal species) less fit. It could then be out-competed by plant species less dependent on AM fungi (Mariotte et al. 2013). Given the potential influence of AM fungi on plant responses to climate change, the direct effects of abiotic stress on the fungi themselves and the consequences for the symbiosis cannot be ignored.

In this study, we present two hypotheses for how abiotic stress influences the ecology and evolution of AM fungi (Table 1). The stress exclusion hypothesis addresses the ecological consequences for an AM fungal community of a relatively short-term abiotic stress, whereas the stress adaptation hypothesis examines the long-term evolutionary consequences of selection by abiotic stress on AM fungi.

\section{The stress exclusion hypothesis}

We hypothesise that abiotic stress will reduce the diversity of AM fungi (Fig. 1). We know that abiotic stress directly affects plant fitness, and abiotic stress can also directly affect the fitness of AM fungi (Fitter et al. 2000; Staddon et al. 2004). AM fungal species vary greatly in functional (Munkvold et al. 2004; Powell et al. 2009), phenotypic, and genetic diversity (Klironomos et al. 2001; Treseder and Allen 2002; Antunes et al. 2011), and thus, we expect that an abiotic stress will affect individual AM fungal species differently, leading to variation in AM fungal fitness. As a result, abiotic stress in this system can act as an environmental filtering process (Vellend 2010; HilleRisLambers et al. 2012). Specifically, depending on the severity and duration of the stress, less-tolerant AM fungal species may be entirely excluded from the community. Thus, we expect abiotic stress to reduce AM fungal diversity and alter AM fungal community composition resulting in an AM fungal community with a higher proportion of species that are more phenotypically similar, because they are more tolerant of that specific abiotic stress.

\section{Assumptions}

We make four main assumptions in this hypothesis (Table 1):

First, we assume that AM fungal communities are diverse The diversity of undisturbed AM fungal communities is well established. Currently, there are around 240 known species in the phylum Glomeromycota (Redecker et al. 2013), but it is likely that there are many more unidentified species (Ohsowski et al. 2014). AM fungal communities contain many species, and single plants may associate with as many as 20 different fungi (Fitter 2005).

Second, we assume that abiotic stresses can affect AM fungi There are several examples where abiotic stress has been shown to directly influence AM fungi. Extra-radical hyphae $(\mathrm{ERH})$ respond directly to temperature and moisture (Allen and Kitajima 2013), and variation in temperature experienced by ERH can also influence intra-radical colonisation by AM fungi (Heinemeyer and Fitter 2004) and nutrient transfer to and growth of host plants (Barrett et al. 2014). However, prolonged warming can cause a reduction in respiration in the extra-radical mycelia (Heinemeyer et al. 2006). By contrast, exposure to winterlike conditions $\left(4^{\circ} \mathrm{C}\right)$ for periods as short as 2 weeks have been shown to cause abnormal germination in Glomus intraradices spores (Juge et al. 2002). These spores grew short, recurved hyphae that are associated with stressful conditions (Rayner and Coates 1987). Extended cold storage ( $>90$ days) maximised proper germination with longer ranged, straight hyphae (Juge et al. 2002). Freezing temperatures also have a negative effect on the extent of colonisation by AM fungi in plant roots (Klironomos et al. 2001). Drought has been shown to have both positive and negative effects on AM fungal colonisation of host plants (Auge 2001; Klironomos et al. 2001), but in some cases, drought has caused a reduction in ERH or even led to the inability of AM fungi to colonise plant roots and, therefore, reduced the fungal fitness (Compant et al. 2010; Neumann et al. 2010). On the other end of the scale, flooding has been shown to reduce AM fungal diversity (Deepika and Kothamasi 2014). Heavy metal pollution has been shown to specifically affect AM fungal ERH by inhibiting their growth (Del Val et al. 1999). Thus, there is extensive evidence that AM fungi are directly affected by abiotic stress (reviewed in Lenoir et al. 2016).

Third, not all AM fungal species respond to abiotic stress in the same way Not all plants respond to abiotic stress equally, so we should not be surprised that not all AM fungi respond to abiotic stress equally. AM fungi are functionally diverse (Munkvold et al. 2004; Powell et al. 2009), and vary both phenotypically and genetically in response to abiotic stress (Klironomos et al. 2001; Treseder and Allen 2002; Antunes et al. 2011), suggesting that abiotic stress likely influences each fungal species differently. This can be linked to differences in AM fungal communities between climatic zones. For example, communities from mesic sites are characterised by the presence of Gigasporaceae and Acaulosporaceae, while communities from semiarid sites are characterised by Glomeraceae and Paraglomaceae (Egerton-Warburton et al. 2007). Rhizophagus irregularis and Claroideoglomus etunicatum increased hyphal and arbuscular colonisation of host plant roots in response to elevated $\mathrm{CO}_{2}$ levels, while Acaulospora denticulata and 


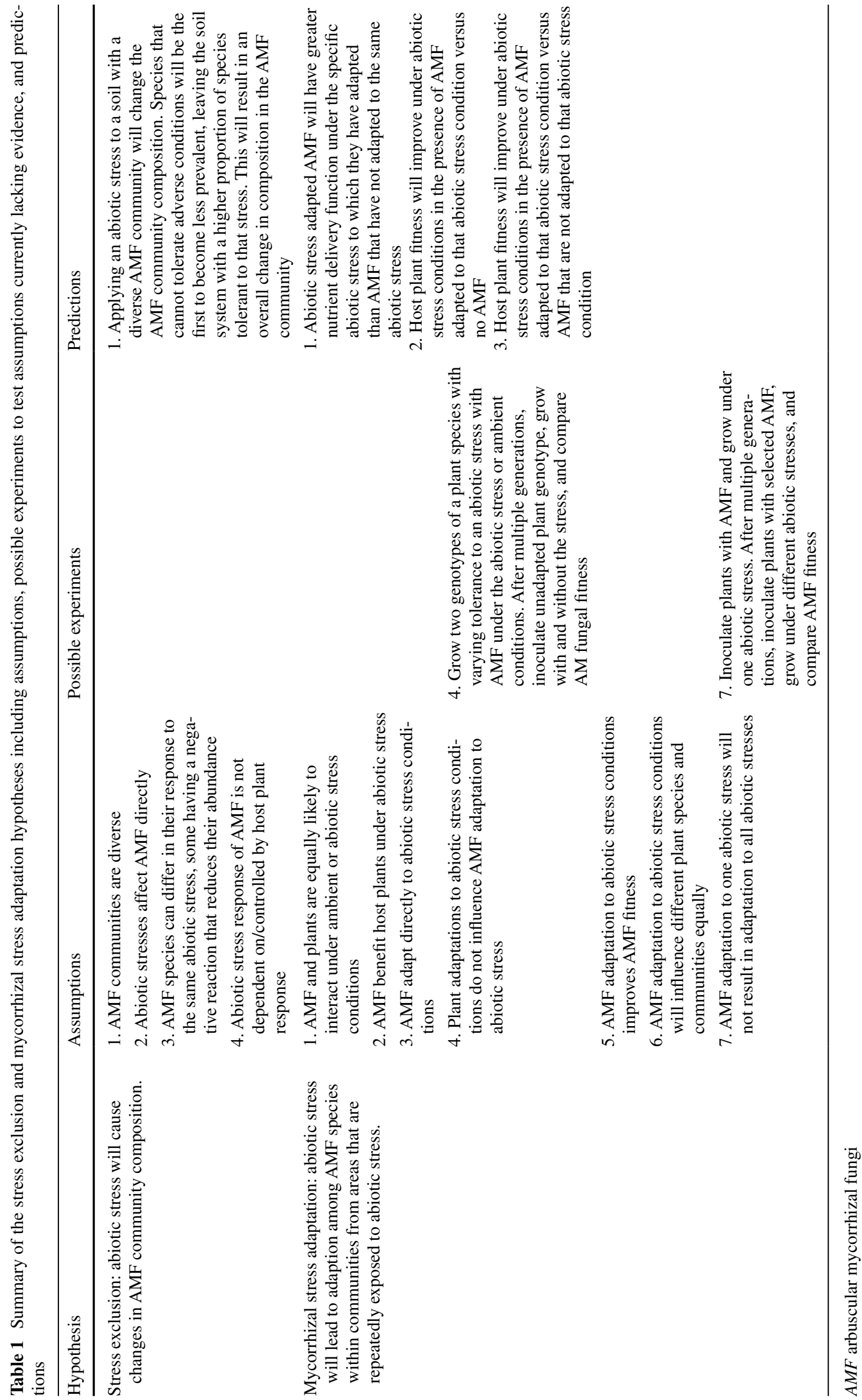




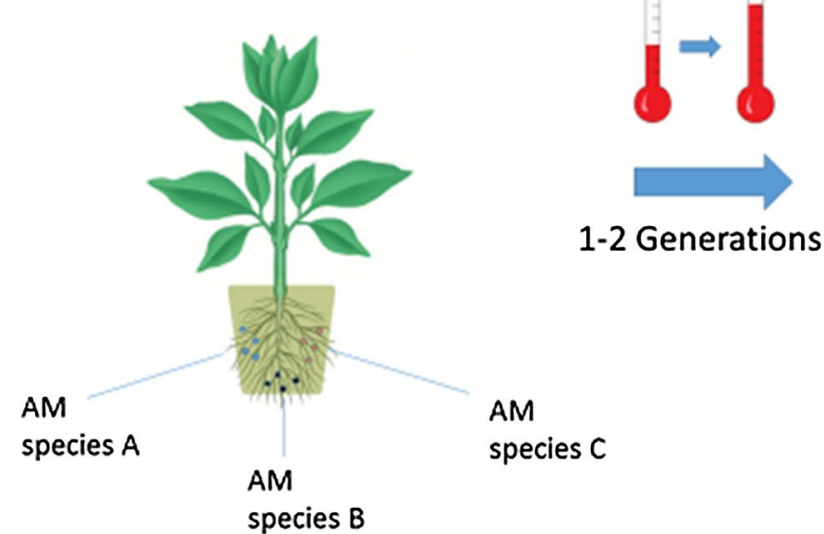

species B

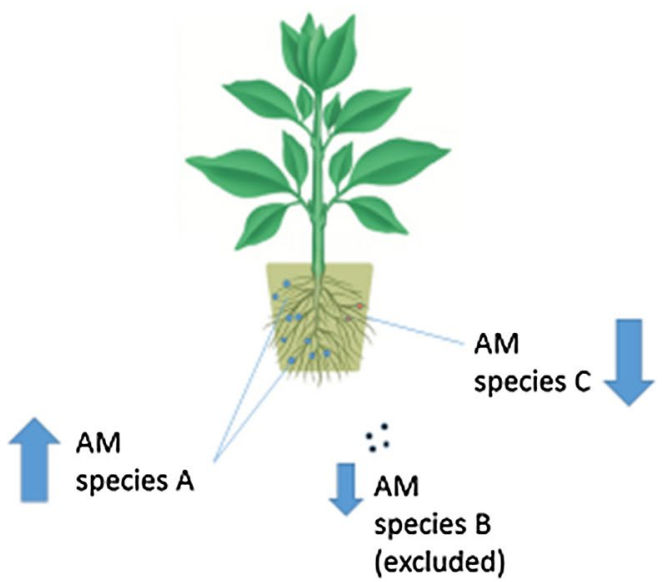

species have varying responses to abiotic stress, species with a poorer tolerance to abiotic stress (such as species B in this figure) will be reduced in abundance or even excluded from the AM fungal community

an added advantage for AM fungal species exposed to frequent, but transient, abiotic stress, because it would allow fungi to maintain fitness but not lose genetic variation useful in the absence of the stress. As a result, those AM fungal species that persist in the face of an abiotic stress may be more plastic than those that do not.

Fourth, we assume that the response of AM fungi to abiotic stress is not controlled by or entirely dependent on the response of the host plant AM fungi are obligate symbionts, and they depend on their hosts for carbohydrates. Given this close relationship, the response of the plant to the abiotic stress cannot be ignored, but it does not override the direct response of the fungi themselves. The ERH and spores of the fungi are exposed directly to the soil conditions. Experiments involving compartmentalised ERH (Heinemeyer and Fitter 2004; Heinemeyer et al. 2006; Barrett et al. 2014) show that AM fungi can respond directly to stresses applied to their ERH without any response from the plant.

\section{Prediction}

With these assumptions in mind, we make the following prediction.

Applying an abiotic stress to a soil system with a diverse AM fungal community will reduce the fitness of certain species of AM fungi, causing them to decrease in abundance or be excluded from the community. This will result in a compositional change in the community.

We expect that some AM fungal species have a poorer tolerance to a given abiotic stress. For example, Glomus spp. has a lower root colonisation under phosphorus enced by phenotypic plasticity within AM fungal species (Behm and Kiers 2014). Phenotypic plasticity would be 
fertilisation than $S$. calospora possibly due to an intolerance of low root carbohydrate concentrations (Pearson et al. 1994). Drought stress halved arbuscule and vesicle formation in Glomus fasciculatum and reduced total root colonisation by a third as compared with Glomus strain ZAC-19. Warming has been shown to have a greater effect on rare species of $\mathrm{AM}$ fungi than more common species in the community, causing a significant reduction in their abundance (Sun et al. 2013) and possibly local extinction for those AM fungal species. Nitrogen and phosphorus fertilisation can significantly reduce the number of operational taxonomic units within an AM fungal community and shift community composition (Camenzind et al. 2014). Communities fertilised with $\mathrm{N}$ show a reduced richness of Diversisporales, while communities fertilised with $\mathrm{P}$ show a reduced richness of Glomerales while combined $\mathrm{N}$ and $\mathrm{P}$ fertilisation lead to losses of rare species (Camenzind et al. 2014). Similarly, chronic N deposition has been shown to significantly reduce the amount of rare AM fungal taxa in a community (van Diepen et al. 2013). Short-term periods of drought can have a stimulatory effect on root colonisation and sporulation of AM fungi, but the lower spore production and species richness of AM fungal communities from arid areas indicate the long-term negative impacts of drought (Auge 2001). Thus, there is evidence from multiple studies of abiotic stress influences on AM fungi to support our prediction (Supplementary Table 1).

At this stage, adaptive phenotypic plasticity may be responsible for the ability of certain species to tolerate an abiotic stress, such as can be seen in the response of $F$. mosseae to varying levels of moisture and heat (Stahl and Christensen 1991). Whether or not the tolerant phenotype persists if the abiotic stress abates will test the potential for reversibility in phenotypic plasticity (Behm and Kiers 2014). Conversely, the reduction of certain species in the community could be due to non-adaptive phenotypic plasticity producing phenotypes that are less able to tolerate the abiotic stress (Ghalambor et al. 2007). Either way, we expect that overall fungal abundance and/or species richness will likely decrease.

One potential modifier of the compositional changes that an abiotic stress will cause could be the dispersal of AM fungal propagules from other locations. AM fungi can be spread to new locations by birds (Nielsen et al. 2016), mammals (Fracchia et al. 2011), and possibly wind in drier habitats (Egan et al. 2014). It appears that the AM fungal species best suited to dispersal produce more spores and have higher colonisation potentials, but also are less competitive and are not as persistent (Nielsen et al. 2016). This suggests that compositional changes caused by abiotic stress are unlikely to be reversed by dispersal. Environmental variables appear to be more important than dispersal in structuring mycorrhizal communities (Lekberg et al. 2007).
However, a particularly extreme, but transient, abiotic stress (such as a flood, or volcanic activity) could provide the circumstances where dispersal would be more important than adaptation for the reestablishment of the AM fungal community. In this case, early successional species may have more of an advantage than stress-tolerant species, but this will be a rare exception rather than the rule.

\section{Mycorrhizal stress adaptation hypothesis}

After an abiotic stress has caused the reduction or exclusion of AM fungal species that have a poorer tolerance to that stress, the community will be left with a higher proportion of species that are better able to tolerate that given stress. If the stress is not transient, then the surviving AM fungal species exposed to abiotic stress will undergo selection and adaptation to that stress. Adaptation to an abiotic stress should improve the fitness of an AM fungal species (Fig. 2). This means that AM fungal communities from areas that repeatedly or continuously experience abiotic stress factors such as drought, salinity, heavy metal pollution, nutrient deposition, and extremes of temperature will contain species that are adapted specifically to their environment and may benefit their hosts more under that abiotic stress condition than non-adapted AM fungal ecotypes (Appoloni et al. 2008; Maček et al. 2011).

\section{Assumptions}

We make seven assumptions in this hypothesis (Table 1):

First, we assume that AM fungi and plants are equally likely to interact under ambient or abiotic stress conditions The association between AM fungi and plants under abiotic stress is well documented. For example, the AM symbiosis is present in well-watered and drought conditions (Morte et al. 2000; Porcel and Ruiz-Lozano 2004; Bárzana et al. 2012), and at high and low temperatures (Klironomos et al. 2001; Bunn et al. 2009). Total root colonisation may not remain constant during abiotic stress, but even relatively low levels of colonisation can support a mutualistic symbiosis (Sochacki et al. 2013). The degree of association may change due to abiotic stress; however, there is significant evidence to suggest that association (regardless of degree) will be maintained.

Second, we assume that AM fungi continue to conduct resource exchange with their host plants when they are exposed to an abiotic stress Here, we assume that during an abiotic stress, AM fungi will also continue to supply their host with nutrients. That is, they will maintain symbiotic function in addition to colonising their host plants.

There is a wealth of information on the ability of AM fungi to benefit plants during abiotic stress conditions 


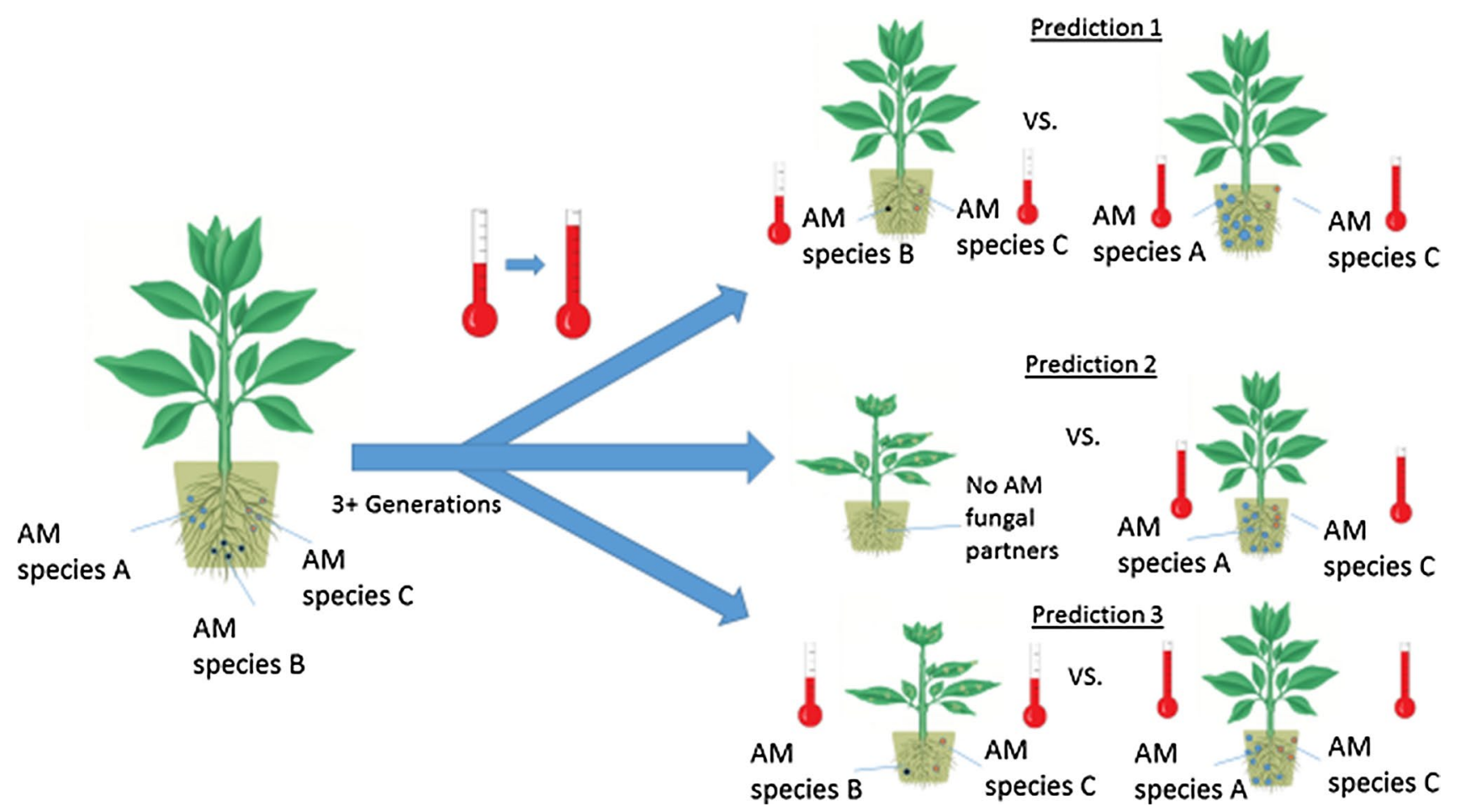

Fig. 2 Representation of the three predictions of the mycorrhizal stress adaptation hypothesis using high temperature as an example abiotic stress. Selection has led to phenotypic changes within three generations in AM fungi in the previous studies (Angelard et al. 2014), and so three generations was used as the cutoff to represent changes due to selection in AM fungi. In the first prediction, stressadapted AM fungal species are expected to maintain a higher level of fitness when exposed to an abiotic stress than unadapted species [as

(Smith and Read 2008), including drought (Aroca and Ruiz-Lozano 2009; Auge 2001), nutrient deficiency (Smith and Read 2008), and salinity (Evelin et al. 2009). An abiotic stress, however, can reduce the benefit provided to plants by AM fungi (such as nutrient excess caused by fertilisation (Johnson 1993) or shading that reduces potential carbon available for allocation to AM fungi (Zheng et al. 2015). This is particularly likely if the cost of supporting an AM fungal partner exceeds the benefit provided by the symbiosis (Johnson 1993, 2010; Johnson et al. 1997; Neuhauser and Fargione 2004), and may lead to reduced allocation to AM fungi by a plant partner (Zheng et al. 2015).

We know of no direct evidence for this assumption, but one could test the assumption in the following way: inoculate plants with a common AM fungal inoculum, and subject half of the plants to an abiotic stress, while the other half are grown under ambient conditions. Allow the plants to grow for multiple generations before isolating the $\mathrm{AM}$ fungi from the soil, and using them to inoculate new plants exposed to the abiotic stress or ambient conditions. Add radioactively labelled phosphorus to pots and compare the phosphorus uptake between plants in both conditions to represented by increases in spore number (a frequent proxy for AM fungal fitness) in the figure]. In the second prediction, plants hosting stress-adapted AM fungal partners are expected to be more tolerant of that stress than plants hosting no AM fungi. Finally, in the third prediction, plants hosting stress-adapted AM fungal partners are expected to be more tolerant to that stress than plants hosting unadapted AM fungal partners. The lack of tolerance in host plants is reflected by stunted growth and leaf spots in this figure

determine whether exposure to abiotic stress has compromised the nutrient delivery function of the AM fungal inocula. If this assumption is true, then nutrient uptake should still occur in plants inoculated with AM fungi previously exposed to abiotic stress.

Third, we assume that AM fungi can respond directly to the effects of abiotic stress Specifically, we assume that abiotic stress will cause selection within AM fungal species, for improved stress tolerance. This can be seen in the response of AM fungi to long-term nutrient deficiency (Johnson et al. 2010; Antunes et al. 2012), drought (Davies et al. 2002), and heavy metal pollution (Del Val et al. 1999). There is a range of mechanisms that AM fungi have developed to deal with abiotic stresses like these. Drought tolerance can be achieved by improved water uptake and protection from protein denaturation (Porcel et al. 2006; Querejeta et al. 2006). Heat shock can be mitigated in a similar fashion (Ocón et al. 2007). Salt tolerance has been hypothesised to result from upregulation of genes encoding chaperones or aquaporins (Estrada et al. 2013). Stress from pollutants like heavy metals can be mitigated by preventing oxidative damage (Lanfranco et al. 2005), and degradation 
(Song et al. 2016), sequestration (González-Chávez et al. 2004), or transportation (Gonzalez-Guerrero et al. 2005) of the pollutants themselves. Thus, abiotic stress appears to select for adapted AM fungal ecotypes.

Fourth, we assume that the host plants' own evolutionary response will not be more important for maintaining the fitness of an AM fungal species than adaptation by an AM fungal species itself If the abiotic stress in question is present over the course of multiple plant generations, then it is likely that the plants will exhibit adaptations of their own (Hirt and Shinozaki 2004). Currently, there is evidence of the beneficial effects that the adaptations of a fungal symbiont can have on their host plants (Rodriguez et al. 2010; Redman et al. 2011; Southworth 2012). However, it is not known what, if any, effect the host plant's own adaptations have on a fungal partner, plant adaptation to abiotic stress will likely be important to the AM fungi, but we expect AM fungal adaptation to be equally (or more) important for maintaining AM fungal fitness under abiotic stress.

Given that there is no direct evidence for this assumption, we propose the following experiment: grow two genotypes of a plant species, varying in adaptation to a particular abiotic stress with a common AM fungal inoculum under abiotic stress or ambient conditions. After multiple generations of plant growth, both selected and unselected AM fungi should be isolated and used to inoculate plants of the unadapted plant genotype and grown with and without the stress. Comparing the fitness of the AM fungi in these conditions will reveal any effects that adaptation by the host plant had on the AM fungi. If this assumption is true, then there should be little difference in the fitness of the AM fungi with and without the abiotic stress. We expect that this experiment will show that AM fungi cannot rely entirely on the adaptations of their host plant, and that adaptations of their own are needed to improve their fitness.

Host plant species are clearly important in structuring AM fungal communities (Eom et al. 2000), but abiotic soil conditions are equally important (Johnson et al. 1992). Vice versa, AM fungal communities can be important in structuring the community of their hosts (van der Heijden et al. 1998). The genetically variable nuclei that AM fungi have give them the potential to respond rapidly to changes in their host plant and their environment (Angelard et al. 2014). In a changing environment, soil microbes may have a greater capacity to adapt than their hosts, given their shorter generation time (Lau and Lennon 2012). This shows that AM fungi, despite being obligate symbionts, can adapt independent of any one particular host plant species, and should not be considered as entirely dependent passengers in the symbiosis.

Fifth, we assume that the adaptation of an AM fungus to an abiotic stress will improve the fitness of that AM fungus
An improvement in fitness will be indicated by an increase in the combined parameters of percent root colonisation, extra-radical hyphal length, and spore number. The best evidence for this is nutrient excess which selects for AM fungal ecotypes with a higher fitness (often measured by a combination of root colonisation and extra-radical hyphae), although these ecotypes are also frequently less mutualistic (Johnson 1993; Johnson et al. 1997; Neuhauser and Fargione 2004). As a result, there is evidence for adaptations to abiotic stress increasing AM fungal fitness.

Sixth, we assume that the adaptations gained by an AM fungal species will improve their fitness and maintain host plant associations independent of the specific host plant species they were associated with when initially exposed to the abiotic stress When an AM fungal species is first exposed to an abiotic stress, it will be associated with a host plant, but we assume that regardless of the initial host species, an AM fungus was associated with during a stress and that AM fungal species will still associate with multiple plant species within a community. When exposed to an abiotic stress, preadapted AM fungi may provide plants with better tolerance. For example, AM fungi isolated from arid soils promoted pepper growth under drought (MenaViolante et al. 2006). A study on the effects of AM fungi from 42 different soils on a novel host plant, Lotus corniculatus L., showed that adaptation to the edaphic factors of an AM fungal site of origin was more important than host identity for promoting a mutualistic relationship (Lambert et al. 1980). Thus, AM fungal adaptation to an abiotic stress will not be dependent upon the host plant, and it was in association with when the abiotic stress was applied.

Seventh, we assume that adaptation to a particular abiotic stress in AM fungi will not result in adaptation to all abiotic stresses Both plants and AM fungi are likely to be exposed to a wide variety of abiotic stresses, but the traits that confer tolerance to a stress in either organism are not likely to provide tolerance to all stresses. Tradeoffs in adaptation to different abiotic stresses have long been documented in all organisms, and therefore, we should expect there to be tradeoffs in adaptation to different abiotic stresses in AM fungi. For example, adaptation to nitrogen and water availability has been shown to appear in different AM fungal strains, but not the same strain (Martinez-Garcia et al. 2015). While some adaptations, such as enhanced osmotic adjustment in roots (Porcel and Ruiz-Lozano 2004), could be useful both during low-water and highsalinity stresses, specific adaptations will not be applicable to all possible abiotic stresses. The same will likely be true for AM fungi.

There are relatively few tests in the literature applicable to this assumption (but see Martinez-Garcia et al. 2015), so we propose the following experiment to test this assumption. Inoculate a number of plants with the same AM fungi 
and grow them under one abiotic stress with all other conditions being non-limiting. For example, plants and AM fungi grown under drought stress should also be grown with optimal temperature, salinity, soil chemistry, and nutrients. After multiple generations of plant growth, isolate the AM fungi from the soil and use as inocula for a new set of plants. Grow replicated inoculated plants under different abiotic stresses. Comparing the fitness of the AM fungi using a metric incorporating spore abundance, intra- and extra-radical hyphal growth, should show whether exposure to one abiotic stress has improved AM fungal tolerance to other abiotic stresses. If this assumption is true, then the fitness of the AM fungi under novel abiotic stresses should be lower than that under the initial abiotic stress. Adaptation to a specific abiotic stress will improve the fitness of an AM fungus, but only under the initial abiotic stress.

\section{Predictions}

With these assumptions in mind, we make three main predictions in this hypothesis.

First, we predict that AM fungi that are adapted to a particular abiotic stress will have greater fitness when exposed to that stress than AM fungi that have not previously been exposed to that stress We expect adaptation to an abiotic stress should promote AM fungal fitness. Again, changes in fitness would be best measured using a metric combining spore abundance, intra- and extra-radical hyphal growth, as AM fungal species are represented at varying levels between these measures (Varela-Cervero et al. 2015). For example, previous research suggests that drought-adapted AM fungi may have spores with a higher drought tolerance (Jacobson 1997) which would increase their fitness when exposed to drought. Adaptation to an abiotic stress will, therefore, improve AM fungal fitness.

The strength of selection can be limited by dispersal (reviewed in Räsänen and Hendry 2008), particularly in the case of microbes (Hanson et al. 2012). AM fungal dispersal is typically limited to belowground hyphal development (Smith and Read 2008), but recent studies have shown that AM fungal spores can be dispersed by wind in arid environments (Egan et al. 2014), rodents (Mangan and Adler 2002; Fracchia et al. 2011), and potentially by birds (Nielsen et al. 2016). However, the rate of dispersal by these mechanisms is low (Egan et al. 2014), suggesting that in many environments, dispersal is unlikely to greatly limit selection. However, in the case of extreme but transient stresses, this low level of dispersal could aid in restoring genetic diversity when an abiotic stress was absent.

While adaptive phenotypic plasticity may have been responsible for a species' survival of an abiotic stress, this does not preclude the possibility for adaptive evolution as well. An adaptive evolutionary response is likely to follow beneficial phenotypic plasticity if the new phenotype is not yet optimal, and because exclusion (or extinction) is made less likely (Ghalambor et al. 2007).

Second, we predict that plants associated with AM fungi preadapted to an abiotic stress will improve under that abiotic stress as compared to plants grown without any AM fungal partners Association with AM fungi is generally more beneficial to plants under abiotic stress (Smith and Read 2008), and preadapted AM fungi have been shown to benefit host plants. For example, AM fungi preadapted to drought improve drought tolerance in plants as compared with plants grown without AM fungi (Marulanda et al. 2007; Sochacki et al. 2013), even when plants not associated with AM fungi were supplied with extra phosphorus (Davies et al. 2002). As a result, we expect stress-adapted AM fungi to benefit host plants (Supplementary Table 1).

Third, we predict that fitness of plants associated with prestress-adapted AM fungi will improve when exposed to that abiotic stress as compared to plants associated with non-adapted AM fungi If adaptation by AM fungi improves fungal fitness, we might expect that benefit to also transfer to host plants, especially in comparison with plants associated with AM fungi that have not undergone adaptation in response to the focal stress. For example, AM fungi from well-watered areas confer less drought tolerance for host plants than AM fungi from drought prone regions (Davies et al. 2002; Martinez-Garcia et al. 2015). AM fungi adapted to serpentine soils have been shown to improve plant growth and phosphorus uptake in serpentine soils as compared with AM fungi from other soils (Doubková et al. 2012). AM fungal adaptations, therefore, likely maintain the fitness of both plants and AM fungi, and these adaptations are likely to become more important with climate changes. The widespread occurrence of abiotic stresses are already a big problem for agriculture (van Velthuizen et al. 2007; Mantri et al. 2011), and thus, AM fungal adaptations could help maintain worldwide food security.

\section{Implications}

Natural plant communities are subjected to abiotic stresses that are associated with their environment, as are their associated AM fungi, and it is important to consider how the symbiosis will affect, and be effected by, these pressures, especially if AM fungi that are adapted to abiotic stress may help alleviate the effects of abiotic stress in host plants.

\section{Plant-fungal community feedbacks}

Some plants are more responsive to particular AM fungal species than others (Hartnett and Wilson 1999), so 
reductions in the abundance of key AM fungal species will in turn reduce the abundance of certain plant species. Dependence on a single AM fungal species within a community may become more common if species identity is important in providing tolerance to an extreme abiotic stress (Rodriguez and Redman 2008; Zabinski and Bunn 2014). It could also be possible for the loss of a plant species to feed back to AM fungal species leading to losses of other important AM fungi from communities. Thus, the loss of one partner in the mycorrhizal symbiosis has the potential to cause the loss of other partner species. High levels of co-dependence in plants and AM fungi will be particularly important during abiotic stress, as the loss or reduction of either partner may intensify the negative effects of an abiotic stress.

AM fungi can alter competition between plant species (Mariotte et al. 2013; Lin et al. 2015). The level of mycorrhizal dependence of plant species in a community can influence how AM fungi alter competitive interactions (Urcelay and Díaz 2003). The right AM fungi can improve the ability of competing plant species to coexist (Klabi et al. 2014), so a reduction in AM fungal abundance or diversity could alter competitive outcomes between plants leading to a change in plant community composition and diversity (Cahill et al. 2008). Plant species that are less dependent on the mycorrhizal symbiosis will have a competitive advantage when AM fungal abundance is reduced (Scheublin et al. 2007), allowing them to become more dominant in the community. Thus, abiotic stress may both directly impact plant and AM fungal communities, but may also indirectly impact both communities via altered feedbacks between partners.

\section{AM fungal adaptation influences on plants}

AM fungal adaptations to abiotic stress will improve AM fungal fitness, and these adaptations could have variable effects on the host plant. Adaptations by AM fungal species to abiotic stress have been hypothesised to have positive (e.g., Martinez-Garcia et al. 2015; Mena-Violante et al. 2006) or negative (e.g., Johnson 1993; Neuhauser and Fargione 2004) consequences for the maintenance of the mutualistic symbiosis (Kiers and van der Heijden 2006; Johnson et al. 1997). Under abiotic stress, nutrient exchange may not be the only mycorrhizal function that influences plant fitness. An AM fungal species may also be considered mutualistic if it provides tolerance to abiotic stress. Abiotic stresses that affect plants by means other than limiting their access to nutrients could promote a mutualistic relationship based on factors other than resource exchange. For example, AM fungi adapted to sites with high concentrations of heavy metals may alleviate plant toxicity by preventing heavy metals from accessing sensitive areas in plant roots, or by excreting metal chelators (Schützendübel and Polle 2002; Miransari 2011; Seguel et al. 2013). Thus, adaptations by AM fungi could result in novel benefits for host plants.

However, changes in AM fungal community composition associated with abiotic stress could alter the functional composition of AM fungal communities as well (Finlay 2008; Feddermann et al. 2010). AM fungi have been hypothesised, like plants, to fall into three life-history categories: competitors, ruderals, and stress-tolerant species (Chagnon et al. 2013). We can imagine that if an ambient community begins with equal proportions of AM fungi of each type of life-history, that an abiotic stress, in accordance with the stress exclusion hypothesis, is likely to shift the proportion of functional types strongly in favour of stress-tolerant species. In this case, the community may lose more ruderal species, or those best able to colonise new hosts in an environment or disperse to new patches, and competitive species. Thus, abiotic stress could limit the range of functions (particularly types of associations with host plants) as well as the abundance of functions within an AM fungal community.

\section{Placing abiotic stress in the broader context of selective forces on AM fungi}

While AM fungal adaptations are likely to influence plants, the reverse, which host plant plays an important role in structuring AM fungal communities (e.g., Eom et al. 2000; Johnson et al. 2004), is also true. Host plant specificity for AM fungal species has partially been credited for this role; however, plants can also affect the abiotic properties of their soil (e.g., Bezemer et al. 2006). As a result, plants could indirectly alter their AM fungal community by changing soil abiotic properties. In addition, many of the adaptations to abiotic stress of plants will also alter soil abiotic properties which could directly or indirectly impact AM fungi. In particular, in very low nutrient environments, plants exude organic acids to release bound nutrients (Lambers et al. 2015), and plants can also increase water availability near the soil surface by growing deep tap roots. As a result, AM fungal associations with plants are likely partially due to specificity and partially due to the abiotic environment created by a host plant.

In addition, to the selective pressures created by abiotic stress and plants, AM fungi also face biotic stress pressures. Very little is known about the direct influence of biotic stress on AM fungal adaptation, despite the presence of fungal grazers, such as Collembola and nematodes. Greater information is available on the influence on AM fungi of biotic stresses on their host plants. Plant herbivory has a range of effects on AM fungi including both increasing and reducing root colonisation, and reduction in species 
diversity (Eom et al. 2001; Gehring and Bennett 2009). Adaptations by AM fungi that improve their host plant's defence response may increase both partners' fitness, but this has rarely been explored in an evolutionary context (but see Bennett et al. 2006; Rasmann et al. 2011). As a result, there is scope for increasing our understanding of the importance of abiotic stress in relation to plant host and biotic stress for driving selection on AM fungi.

\section{Climate change}

With the advance of climate change, plants will be exposed to more extreme abiotic stresses (Fitzpatrick et al. 2008; Lindner et al. 2010; Benito et al. 2014). Increased abiotic stress will likely affect the geographic ranges of plants, and could increase the impact on AM fungi due to their reduced ability to migrate in response to a changing environment (Fitter et al. 2000). The diversity and abundance of AM fungi and plants are correlated, so we expect that a change in one partner will lead to a change in diversity or abundance of the other partner. This correlation will be particularly important given the potential for AM fungi to mediate the response of plants to climate change (Mohan et al. 2014), so any changes in the AM fungal community, particularly if they lead to changes in AM fungal function, are sure to have repercussions for plants. Even under ambient conditions, changes in the composition of an AM fungal community can affect the composition of a plant community (van der Heijden et al. 1998; Pellissier et al. 2013). Climate changes will likely alter the diversity of both plants and AM fungi and the dominant species in both communities could change. If abiotic stress caused by climate changes reduces AM fungal abundance, it is likely that non-mycotrophic plants will benefit more than mycotrophic plants, as some non-mycotrophic plants, such as Salsola kali, can be suppressed by AM fungi (Antoninka et al. 2009). The presence of non-mycotrophic plants can make it difficult for arid sites to be recolonised by mycotrophic plants. For example, plants like garlic mustard can suppress AM fungi in the soil and make it harder for mycotrophic plants to associate with them (Roberts and Anderson 2001; Koch et al. 2011; Lankau et al. 2014). Unlike non-mycotrophic plants, mycotrophic plants may require AM fungi to survive abiotic stress conditions (Allen and Allen 1988; Olsson and Tyler 2004; Lambers et al. 2015). In this way, climate changes could cause a sequence of positive feedbacks that further reduce AM fungal abundance and diversity and increase impacts on plant communities.

With the potential for both the expansion and reduction in ranges of certain plants, a shift in dominance toward $\mathrm{C}_{4}$ plants, and changes in AM fungal community composition, it is clear that climate changes will significantly alter natural plant and soil systems. Climate changes could lead to an increased abundance of $\mathrm{C}_{4}$ plants due to their greater ability to take advantage of elevated levels of $\mathrm{CO}_{2}$ (Bloom et al. 2012; Morgan et al. 2011; Pendall et al. 2011). This could have a positive effect on AM fungal abundance, because $\mathrm{C}_{4}$ plants have been shown to be more responsive to AM fungi (Hetrick et al. 1990; Bennett et al. 2013). In addition to higher responses to AM fungi, elevated levels of $\mathrm{CO}_{2}$ can also stimulate $\mathrm{AM}$ fungal colonisation in $\mathrm{C}_{4}$ more than in $\mathrm{C}_{3}$ plants (Monz et al. 1994). Elevated atmospheric $\mathrm{CO}_{2}$, warming, and decreased precipitation are inter-related consequences of climate changes, but they do not all affect AM fungi and plants in the same way. Thus, we cannot accurately predict effects of climate changes, but it is possible that elevated $\mathrm{CO}_{2}$ levels could promote $\mathrm{C}_{4}$ plants and AM fungi (Morgan et al. 2011).

The loss of important AM fungal species could have particularly strong consequences for agricultural systems in the face of climate change. Agricultural soil generally has AM fungal communities with low diversity due to intensive farming techniques (Alguacil et al. 2008; Verbruggen and Kiers 2010). Climate change is likely to intensify existing abiotic stresses and broaden the geographical range over which they affect both agricultural and natural soil systems (Lane and Jarvis 2007; Allen et al. 2010). This means that we can expect agricultural systems to be exposed to abiotic stresses like heat and drought more frequently, particularly in tropical regions (Mendelsohn and Dinar 1999). Reductions in AM fungal diversity and abundance with intensive farming practices may limit the evolutionary potential of AM fungi and the ability of the AM fungi in agricultural soil to adapt to abiotic stresses.

\section{Invasive species}

While climate change can reduce the range of some plant species, the range of other species is increasing, particularly invasive species (Dukes and Mooney 1999; Bradley et al. 2009; Diez et al. 2012; Vicente et al. 2013). We cannot make precise predictions about how an AM fungal community would react to an invasive species in the context of abiotic stress, but it is likely that further compositional changes would be induced. Reductions in diversity of AM fungi in response to invasive species have been observed previously (Hawkes et al. 2006; Mummey and Rillig 2006; Vogelsang and Bever 2009; Shannon et al. 2014). The influence of abiotic stress on invasive species will depend on the prevailing conditions of the area they originated from, and their ability to rapidly adapt to a new environment that may also be changing. Invasive species have been noted for their ability to adapt to new environments (Prentis et al. 2008), but it is hard to predict how they interact with AM fungi. 
Many invasive plants do not form mycorrhizas (Pringle et al. 2009), while some do and are assisted by them (Marler et al. 1999; Reinhart and Callaway 2006; Nuñez et al. 2009). However, the reduction in density and diversity of AM fungi often associated with plant invasions (Mummey and Rillig 2006; Vogelsang and Bever 2009) could limit the ability of AM fungi in those systems to adapt to abiotic stresses. Any reduction in diversity or abundance of $\mathrm{AM}$ fungi will reduce the genetic variation within the AM fungal community, and this will limit their evolutionary potential (England et al. 2003). In addition, any reduction in the abundance, diversity, and evolutionary potential of AM fungi will have consequences for the survival of both above- and belowground communities, especially during an abiotic stress.

\section{Possible utilisation of adapted AM fungi}

Adaptation to a particular abiotic stress could be taken advantage of, for example, in creating commercial AM fungal inocula. Adaptation by AM fungi creates opportunities for suppliers to produce inocula that improve the stress tolerance of a crop. Inoculating field soils with AM fungi has been shown to be effective for improving the yield of various crops under relatively benign conditions (Bagyaraj and Manjunath 1980; Pellegrino et al. 2011; Ortas 2012; Ceballos et al. 2013) and under abiotic stress (Gholamhoseini et al. 2013). Creating an AM fungal inoculum that is tailored to an abiotic stress could be a sustainable strategy to help farmers in regions where agriculture is restricted by an abiotic stress. Similarly, restoration efforts could be aided by not only inoculating with an AM fungal inoculate prior to reintroduction to the field (Richter and Stutz 2002), but by inoculating with AM fungi with abiotic stress tolerance needed for the restored environment. Ecotypes such as these could be used as an alternative to ecotypes from AM fungal banks that do not control the abiotic stresses from the source of their inocula. Another avenue in restoration using stress-adapted AM fungi could be in the phytoremediation of soils polluted by heavy metals like $\mathrm{Cu}, \mathrm{Zn}, \mathrm{Pb}$, $\mathrm{Co}$, and $\mathrm{Cd}$. This involves the use of metal-accumulating plants to reduce the level of heavy metals in soils contaminated by nearby mines or the overuse of sewage sludge (Suchkova et al. 2010). This is cheaper and more environmentally friendly than other methods like the use of chemicals (Chen et al. 2000). Using AM fungi that have adapted to heavy metal toxicity can further improve phytoremediation by helping the plants survive, for example, $\mathrm{Cu}$ or $\mathrm{Zn}$ pollution (Orłowska et al. 2005; Meier et al. 2011, 2015).

While mycorrhizae are ubiquitous in nature, there are opportunities for their addition to both agricultural and natural systems, particularly when the AM fungal community of an area is degraded or unadapted.

\section{Stress-adapted AM fungi in non-stressed conditions}

What happens to AM fungal fitness when a long-term abiotic stress ends? An example could be when long-term droughts, as in Southern California, end. When an AM fungus becomes well adapted to an abiotic stress, it will likely become a dominant ecotype in the community. In the hypoxic soils found in $\mathrm{CO}_{2}$ springs, two $\mathrm{AM}$ fungal phylotypes were found exclusively in hypoxic soil and were significantly more abundant in the community than other phylotypes found outside the $\mathrm{CO}_{2}$ springs (Maček et al. 2011). If the $\mathrm{CO}_{2}$ springs were to disappear from that site would these adapted ecotypes lose their competitive advantage? We predict these "adapted" ecotypes would likely be reduced in abundance in the community as other ecotypes perhaps better suited to the "new" environment outcompete them. If the stress periodically returns, they may still persist in the community (Fitter et al. 2000), but perhaps not as abundant as before the loss of the stress. AM fungi have demonstrated a remarkable ability to adapt to extreme environments, but such a degree of adaptation could diminish their ability to survive outside those environments.

\section{Conclusions}

We conclude that AM fungi are important for improving plant tolerance to abiotic stress, but also respond to abiotic stress independently of their host plant. Abiotic stresses affect the abundance and community composition of AM fungi. Changes in the diversity of AM fungi will feed back into the plant community and cause corresponding changes in diversity and dominant plant species, and these feedbacks will become stronger with climate changes, agriculture, and plant invasions. AM fungi are capable of adapting to the abiotic environment which may or may not improve their mutualistic function. The impact of the ecological and evolutionary responses of AM fungi to abiotic stresses is likely to become even more important for both natural and agricultural systems in the face of climate changes and biotic stresses, such as invasion by non-native species.

Acknowledgments The authors would like to thank Alison Karley, Rohan Riley, and Philip Smith for comments on the manuscript, and acknowledge funding support from the Scottish Government Rural and Environment Research and Analysis Directorate (RESAS) Work package Themes one and three.

Author contribution statement NSM and AEB conceived of the hypotheses. NSM and AEB wrote the manuscript.

Open Access This article is distributed under the terms of the Creative Commons Attribution 4.0 International License (http://creativecommons.org/licenses/by/4.0/), which permits unrestricted use, distribution, and reproduction in any medium, provided you give 
appropriate credit to the original author(s) and the source, provide a link to the Creative Commons license, and indicate if changes were made.

\section{References}

Alguacil MM, Lumini E, Roldán A et al (2008) The impact of tillage practices on arbuscular mycorrhizal fungal diversity in subtropical crops. Ecol Appl 18:527-536. doi:10.1890/07-0521.1

Al-Karaki GN (2000) Growth of mycorrhizal tomato and mineral acquisition under salt stress. Mycorrhiza 10:51-54

Allen EB, Allen MF (1988) Facilitation of Succession by the Nonmycotrophic Colonizer Salsola kali (Chenopodiaceae) on a harsh site: effects of mycorrhizal fungi. Am J Bot 75:257-266

Allen MF, Kitajima K (2013) In situ high-frequency observations of mycorrhizas. New Phytol 200:222-228. doi:10.1111/nph.12363

Allen CD, Macalady AK, Chenchouni H et al (2010) A global overview of drought and heat-induced tree mortality reveals emerging climate change risks for forests. For Ecol Manag 259:660684. doi:10.1016/j.foreco.2009.09.001

Angelard C, Tanner CJ, Fontanillas P et al (2014) Rapid genotypic change and plasticity in arbuscular mycorrhizal fungi is caused by a host shift and enhanced by segregation. ISME J 8:284-294. doi:10.1038/ismej.2013.154

Antoninka A, Wolf JE, Bowker M et al (2009) Linking aboveand belowground responses to global change at community and ecosystem scales. Glob Chang Biol 15:914-929. doi:10.1111/j.1365-2486.2008.01760.x

Antoninka AJ, Ritchie ME, Johnson NC (2015) The hidden Serengeti-Mycorrhizal fungi respond to environmental gradients. Pedobiologia (Jena) 58:165-176. doi:10.1016/j. pedobi.2015.08.001

Antunes PM, Koch AM, Morton JB et al (2011) Evidence for functional divergence in arbuscular mycorrhizal fungi from contrasting climatic origins. New Phytol 189:507-514. doi:10.1111/j.1469-8137.2010.03480.x

Antunes PM, Lehmann A, Hart MM et al (2012) Long-term effects of soil nutrient deficiency on arbuscular mycorrhizal communities. Funct Ecol 26:532-540. doi:10.1111/j.1365-2435.2011.01953.x

Appoloni S, Lekberg Y, Tercek MT et al (2008) Molecular community analysis of arbuscular mycorrhizal fungi in roots of geothermal soils in Yellowstone National Park (USA). Microb Ecol 56:649659. doi:10.1007/s00248-008-9384-9

Aroca R, Ruiz-Lozano JM (2009) Induction of plant tolerance to semi-arid environments by beneficial soil microorganismsa review. In: Lichtfouse E (ed) Climate change, intercropping, pest control and beneficial microrganisms, sustainable agriculture reviews, vol 2. Springer, Dordrecht, pp 121-135

Audet P, Charest C (2007) Dynamics of arbuscular mycorrhizal symbiosis in heavy metal phytoremediation: meta-analytical and conceptual perspectives. Environ Pollut 147:609-614. doi:10.1016/j.envpol.2006.10.006

Auge RM (2001) Water relations, drought and vesicular-arbuscular mycorrhizal symbiosis. Mycorrhiza 11:3-42. doi:10.1007/ s005720100097

Bagyaraj DJ, Manjunath A (1980) Response of crop plants to VA mycorrhizal inoculation in an unsterile indian soil. New Phytol 85:33-36. doi:10.1111/j.1469-8137.1980.tb04445.x

Barrett G, Campbell CD, Hodge A (2014) The direct response of the external mycelium of arbuscular mycorrhizal fungi to temperature and the implications for nutrient transfer. Soil Biol Biochem 78:109-117

Bárzana G, Aroca R, Paz JA et al (2012) Arbuscular mycorrhizal symbiosis increases relative apoplastic water flow in roots of the host plant under both well-watered and drought stress conditions. Ann Bot 109:1009-1017. doi:10.1093/aob/mcs007

Behm JE, Kiers ET (2014) A phenotypic plasticity framework for assessing intraspecific variation in arbuscular mycorrhizal fungal traits. J Ecol 102:315-327. doi:10.1111/1365-2745.12194

Benito BM, Lorite J, Pérez-Pérez R et al (2014) Forecasting plant range collapse in a mediterranean hotspot: when dispersal uncertainties matter. Divers Distrib 20:72-83. doi:10.1111/ddi.12148

Bennett AE, Alers-Garcia J, Bever JD (2006) Three-way interactions among mutualistic mycorrhizal fungi, plants, and plant enemies: hypotheses and synthesis. Am Nat 167:141-152. doi: $10.1086 / 499379$

Bennett AE, Daniell TJ, White PJ (2013) Benefits of breeding crops for yield response to soil organisms. In: de Bruijn FJ (ed) Molecular microbial biology of the rhizosphere, vol 1. WileyBlackwell, Hoboken, NewJersey, USA, pp 17-27

Bezemer TM, Lawson CS, Hedlund K et al (2006) Plant species and functional group effects on abiotic and microbial soil properties and plant-soil feedback responses in two grasslands. J Ecol 94:893-904. doi:10.1111/j.1365-2745.2006.01158.x

Bloom AJ, Asensio JSR, Randall L et al (2012) $\mathrm{CO}_{2}$ enrichment inhibits shoot nitrate assimilation in $\mathrm{C}_{3}$ but not $\mathrm{C}_{4}$ plants and slows growth under nitrate in $\mathrm{C}_{3}$ plants. Ecology 93:355-367. doi:10.1890/11-0485.1

Borriello R, Berruti A, Lumini E et al (2015) Edaphic factors trigger diverse AM fungal communities associated to exotic camellias in closely located Lake Maggiore (Italy) sites. Mycorrhiza 25:253-265. doi:10.1007/s00572-014-0605-4

Bradley BA, Oppenheimer M, Wilcove DS (2009) Climate change and plant invasions: restoration opportunities ahead? Glob Chang Biol 15:1511-1521. doi:10.1111/j.1365-2486.2008.01824.x

Bunn R, Lekberg Y, Zabinski C (2009) Arbuscular mycorrhizal fungi ameliorate temperature stress in thermophilic plants. Ecology 90:1378-1388. doi:10.1890/07-2080.1

Cahill JF Jr, Elle E, Smith GR, Shore BH (2008) Disruption of a belowground mutualism alters interactions between plants and their floral visitors. Ecology 89:1791-1801. doi:10.1890/07-0719.1

Camenzind T, Hempel S, Homeier J et al (2014) Nitrogen and phosphorus additions impact arbuscular mycorrhizal abundance and molecular diversity in a tropical montane forest. Glob Chang Biol 20:3646-3659. doi:10.1111/gcb.12618

Ceballos I, Ruiz M, Fernández C et al (2013) The in vitro mass-produced model mycorrhizal fungus, Rhizophagus irregularis, significantly increases yields of the globally important food security crop cassava. PLoS ONE 8(8):e70633. doi:10.1371/journal. pone.0070633

Chagnon PL, Bradley RL, Maherali H, Klironomos JN (2013) A trait-based framework to understand life history of mycorrhizal fungi. Trends Plant Sci 18:484-491

Chagnon PL, Bradley RL, Klironomos JN (2015) Trait-based partner selection drives mycorrhizal network assembly. Oikos 124:1609-1616. doi:10.1111/oik.01987

Chen HM, Zheng CR, Tu C, Shen ZG (2000) Chemical methods and phytoremediation of soil contaminated with heavy metals. Chemosphere 41:229-234. doi:10.1016/S0045-6535(99)00415-4

Chen S, Jin W, Liu A et al (2013) Arbuscular mycorrhizal fungi (AMF) increase growth and secondary metabolism in cucumber subjected to low temperature stress. Sci Hortic (Amst) 160:222-229. doi:10.1016/j.scienta.2013.05.039

Compant S, Van Der Heijden MGA, Sessitsch A (2010) Climate change effects on beneficial plant-microorganism interactions. FEMS Microbiol Ecol 73:197-214. doi:10.1111/j.1574-6941.2010.00900.x

Cramer GR, Urano K, Delrot S et al (2011) Effects of abiotic stress on plants: a systems biology perspective. BMC Plant Biol 11:163. doi:10.1186/1471-2229-11-163 
Davies FT Jr, Olalde-Portugal V, Aguilera-Gomez L et al (2002) Alleviation of drought stress of Chile ancho pepper (Capsicum annuиm L. cv. San Luis) with arbuscular mycorrhiza indigenous to Mexico. Sci Hortic (Amst) 92:347-359. doi:10.1016/ S0304-4238(01)00293-X

De Deyn GB, Quirk H, Bardgett RD (2011) Plant species richness, identity and productivity differentially influence key groups of microbes in grassland soils of contrasting fertility. Biol Lett 7:75-78. doi:10.1098/rsbl.2010.0575

Deepika S, Kothamasi D (2014) Soil moisture-a regulator of arbuscular mycorrhizal fungal community assembly and symbiotic phosphorus uptake. Mycorrhiza 25:67-75. doi:10.1007/ s00572-014-0596-1

Del Val C, Barea JM, Azcón-Aguilar C (1999) Assessing the tolerance to heavy metals of arbuscular mycorrhizal fungi isolated from sewage sludge-contaminated soils. Appl Soil Ecol 11:261-269. doi:10.1016/S0929-1393(98)00153-X

Diez JM, D'Antonio CM, Dukes JS et al (2012) Will extreme climatic events facilitate biological invasions? Front Ecol Environ 10:249-257

Doubková P, Suda J, Sudová R (2012) The symbiosis with arbuscular mycorrhizal fungi contributes to plant tolerance to serpentine edaphic stress. Soil Biol Biochem 44:56-64. doi:10.1016/j. soilbio.2011.09.011

Dukes JS, Mooney HA (1999) Does global change increase the success of biological invaders? Trends Ecol Evol 14:135-139

Egan C, Li DW, Klironomos J (2014) Detection of arbuscular mycorrhizal fungal spores in the air across different biomes and ecoregions. Fungal Ecol 12:26-31. doi:10.1016/j.funeco.2014.06.004

Egerton-Warburton LM, Johnson NC, Allen EB (2007) Mycorrhizal community dynamics following nitrogen fertilization: a crosssite test in five grasslands. Ecol Monogr 77:527-544

England PR, Osler GHR, Woodworth LM et al (2003) Effects of intense versus diffuse population bottlenecks on microsatellite genetic diversity and evolutionary potential. Conserv Genet 4:595-604. doi:10.1023/A:1025639811865

Eom AH, Hartnett DC, Wilson GWT (2000) Host plant species effects on arbuscular mycorrhizal fungal communities in tallgrass prairie. Oecologia 122:435-444. doi:10.1007/s004420050050

Eom AH, Wilson GWT, Hartnett DC (2001) Effects of ungulate grazers on arbuscular mycorrhizal symbiosis and fungal community structure in tallgrass prairie. Mycologia 93:233-242. doi: $10.2307 / 3761643$

Estrada B, Barea JM, Aroca R, Ruiz-Lozano JM (2013) A native Glomus intraradices strain from a Mediterranean saline area exhibits salt tolerance and enhanced symbiotic efficiency with maize plants under salt stress conditions. Plant Soil 366:333-349. doi:10.1007/s11104-012-1409-y

Evelin H, Kapoor R, Giri B (2009) Arbuscular mycorrhizal fungi in alleviation of salt stress: a review. Ann Bot 104:1263-1280. doi:10.1093/aob/mcp251

Feddermann N, Finlay R, Boller T, Elfstrand M (2010) Functional diversity in arbuscular mycorrhiza-the role of gene expression, phosphorus nutrition and symbiotic efficiency. Fungal Ecol 3:1-8

Finlay RD (2008) Ecological aspects of mycorrhizal symbiosis: with special emphasis on the functional diversity of interactions involving the extraradical mycelium. J Exp Bot 59:1115-1126. doi:10.1093/jxb/ern059

Fitter AH (2005) Darkness visible: reflections on underground ecology. J Ecol 93:231-243. doi:10.1111/j.1365-2745.2005.00990.x

Fitter AH, Heinemeyer A, Staddon PL (2000) The impact of elevated $\mathrm{CO}_{2}$ and global climate change on arbuscular mycorrhizas: a mycocentric approach. New Phytol 147:179-187. doi:10.1046/j.1469-8137.2000.00680.x
Fitzpatrick MC, Gove AD, Sanders NJ, Dunn RR (2008) Climate change, plant migration, and range collapse in a global biodiversity hotspot: the Banksia (Proteaceae) of Western Australia. Glob Chang Biol 14:1337-1352. doi:10.1111/j.1365-2486.2008.01559.x

Fracchia S, Krapovickas L, Aranda-Rickert A, Valentinuzzi VS (2011) Dispersal of arbuscular mycorrhizal fungi and dark septate endophytes by Ctenomys cf. knighti (Rodentia) in the northern Monte Desert of Argentina. J Arid Environ 75:1016-1023. doi:10.1016/j.jaridenv.2011.04.034

Gehring C, Bennett A (2009) Mycorrhizal fungal-plant-insect interactions: the importance of a community approach. Environ Entomol 38:93-102. doi:10.1603/022.038.0111

Ghalambor CK, McKay JK, Carroll SP, Reznick DN (2007) Adaptive versus non-adaptive phenotypic plasticity and the potential for contemporary adaptation in new environments. Funct Ecol 21:394-407. doi:10.1111/j.1365-2435.2007.01283.x

Gholamhoseini M, Ghalavand A, Dolatabadian A et al (2013) Effects of arbuscular mycorrhizal inoculation on growth, yield, nutrient uptake and irrigation water productivity of sunflowers grown under drought stress. Agric Water Manag 117:106-114. doi:10.1016/j.agwat.2012.11.007

González-Chávez MC, Carrillo-González R, Wright SF, Nichols KA (2004) The role of glomalin, a protein produced by arbuscular mycorrhizal fungi, in sequestering potentially toxic elements. Environ Pollut 130:317-323. doi:10.1016/j.envpol.2004.01.004

Gonzalez-Guerrero M, Azcon-Aguilar C, Mooney M et al (2005) Characterization of a Glomus intraradices gene encoding a putative $\mathrm{Zn}$ transporter of the cation diffusion facilitator family. Fungal Genet Biol 42:130-140. doi:10.1016/j.fgb.2004.10.007

Hajiboland R, Aliasgharzadeh N, Laiegh SF, Poschenrieder C (2009) Colonization with arbuscular mycorrhizal fungi improves salinity tolerance of tomato (Solanum lycopersicum L.) plants. Plant Soil 331:313-327. doi:10.1007/s11104-009-0255-z

Hanson PJ, Weltzin JF (2000) Drought disturbance from climate change: response of United States forests. Sci Total Environ 262:205-220. doi:10.1016/S0048-9697(00)00523-4

Hanson CA, Fuhrman JA, Horner-Devine MC, Martiny JBH (2012) Beyond biogeographic patterns: processes shaping the microbial landscape. Nat Rev Microbiol. doi:10.1038/nrmicro2795

Hartnett DC, Wilson GWT (1999) Mycorrhizae influence plant community structure and diversity in tallgrass prairie. Ecology 80:1187-1195. doi:10.1890/0012-9658(1999)080\{[\}1187:MIP CSA]2.0.CO;2

Hausmann NT, Hawkes CV (2009) Plant neighborhood control of arbuscular mycorrhizal community composition. New Phytol 183:1188-1200. doi:10.1111/j.1469-8137.2009.02882.x

Hawkes CV, Belnap J, D'Antonio C, Firestone MK (2006) Arbuscular mycorrhizal assemblages in native plant roots change in the presence of invasive exotic grasses. Plant Soil 281:369-380. doi:10.1007/s11104-005-4826-3

Heinemeyer A, Fitter AH (2004) Impact of temperature on the arbuscular mycorrhizal (AM) symbiosis: growth responses of the host plant and its AM fungal partner. J Exp Bot 55:525-534. doi:10.1093/jxb/erh049

Heinemeyer A, Ineson P, Ostle N, Fitter AH (2006) Respiration of the external mycelium in the arbuscular mycorrhizal symbiosis shows strong dependence on recent photosynthates and acclimation to temperature. New Phytol 171:159-170. doi:10.1111/j.1469-8137.2006.01730.x

Hetrick BAD, Wilson GWT, Todd TC (1990) Differential responses of $\mathrm{C}_{3}$ and $\mathrm{C}_{4}$ grasses to mycorrhizal symbiosis, phosphorus fertilization, and soil microorganisms. Can J Bot 68:461-467. doi:10.1139/b90-061 
HilleRisLambers J, Adler PB, Harpole WS et al (2012) Rethinking community assembly through the lens of coexistence theory. Annu Rev Ecol Evol Syst 43:227-248. doi:10.1146/ annurev-ecolsys-110411-160411

Hinsinger P, Plassard C, Tang C, Jaillard B (2003) Origins of rootmediated $\mathrm{pH}$ changes in the rhizosphere and their responses to environmental constraints: a review. Plant Soil 248:43-59

Hirt H, Shinozaki K (eds) (2004) Plant responses to abiotic stress. Springer, Newyork

Hoeksema JD, Chaudhary VB, Gehring CA et al (2010) A metaanalysis of context-dependency in plant response to inoculation with mycorrhizal fungi. Ecol Lett 13:394-407

Jacobson KM (1997) Moisture and substrate stability determine VAmycorrhizal fungal community distribution and structure in an arid grassland. J Arid Environ 35:59-75

Johnson NC (1993) Can fertilization of soil select less mutualistic mycorrhizae? Ecol Appl 3:749-757

Johnson NC (2010) Resource stoichiometry elucidates the structure and function of arbuscular mycorrhizas across scales. New Phytol 185:631-647. doi:10.1111/j.1469-8137.2009.03110.x

Johnson NC, Tilman D, Wedin D (1992) Plant and soil controls on mycorrhizal fungal communities. Ecology 73:2034-2042

Johnson NC, Graham JH, Smith FA (1997) Functioning of mycorrhizal associations along the mutualism-parasitism continuum. New Phytol 135:575-585. doi:10.1046/j.1469-8137.1997.00729.x

Johnson D, Vandenkoornhuyse PJ, Leake JR et al (2004) Plant communities affect arbuscular mycorrhizal fungal diversity and community composition in grassland microcosms. New Phytol 161:503-515. doi:10.1046/j.1469-8137.2003.00938.x

Johnson NC, Wilson GWT, Bowker MA et al (2010) Resource limitation is a driver of local adaptation in mycorrhizal symbioses. Proc Natl Acad Sci USA 107:2093-2098. doi:10.1073/ pnas.0906710107

Johnson NC, Wilson G, Wilson J et al (2014) Mycorrhizal phenotypes and the law of the minimum. New Phytol 205:1473-1484

Juge C, Samson J, Bastien C et al (2002) Breaking dormancy in spores of the arbuscular mycorrhizal fungus Glomus intraradices: a critical cold-storage period. Mycorrhiza 12:37-42. doi:10.1007/s00572-001-0151-8

Kiers ET, Van Der Heijden MGA (2006) Mutualistic stability in the arbuscular mycorrhizal symbiosis: exploring hypotheses of evolutionary cooperation. Ecology 87:1627-1636

Klabi R, Hamel C, Schellenberg MP et al (2014) Interaction between legume and arbuscular mycorrhizal fungi identity alters the competitive ability of warm-season grass species in a grassland community. Soil Biol Biochem 70:176-182. doi:10.1016/j. soilbio.2013.12.019

Klabi R, Bell TH, Hamel C et al (2015) Plant assemblage composition and soil $\mathrm{P}$ concentration differentially affect communities of AM and total fungi in a semi-arid grassland. FEMS Microbiol Ecol 91:1-13. doi:10.1093/femsec/fiu015

Klironomos JN, Ursic M, Rillig M, Allen MF (1998) Interspecific differences in the response of arbuscular mycorrhizal fungi to Artemisia tridentata grown under elevated atmospheric $\mathrm{CO}_{2}$. New Phytol 138:599-605

Klironomos JN, Hart MM, Gurney JE, Moutoglis P (2001) Interspecific differences in the tolerance of arbuscular mycorrhizal fungi to freezing and drying. Can J Bot 79:1161-1166. doi:10.1139/ cjb-79-10-1161

Koch AM, Antunes PM, Barto EK et al (2011) The effects of arbuscular mycorrhizal (AM) fungal and garlic mustard introductions on native AM fungal diversity. Biol Invasions 13:1627-1639. doi:10.1007/s10530-010-9920-7

Koch AM, Antunes PM, Klironomos JN (2012) Diversity effects on productivity are stronger within than between trophic groups in the arbuscular mycorrhizal symbiosis. PLoS ONE. doi:10.1371/ journal.pone. 0036950

Koyama H, Toda T, Hara T (2001) Brief exposure to low-pH stress causes irreversible damage to the growing root in Arabidopsis thaliana: pectin-Ca interaction may play an important role in proton rhizotoxicity. J Exp Bot 52:361-368. doi:10.1093/ jexbot/52.355.361

Lambers H, Martinoia E, Renton M (2015) Plant adaptations to severely phosphorus-impoverished soils. Curr Opin Plant Biol 25:23-31. doi:10.1016/j.pbi.2015.04.002

Lambert DH, Cole H, Baker DE (1980) Adaptation of vesicular-arbuscular mycorrhizae to edaphic factors. New Phytol 85:513-520

Lane A, Jarvis A (2007) Changes in climate will modify the geography of crop suitability: agricultural biodiversity can help with adaptation. SAT eJ 4:1-12. doi:10.3914/ICRISAT.0094

Lanfranco L, Novero M, Bonfante P (2005) The mycorrhizal fungus Gigaspora margarita possesses a CuZn superoxide dismutase that is up-regulated during symbiosis with legume hosts. Plant Physiol 137:1319-1330. doi:10.1104/pp.104.050435

Lankau RA, Bauer JT, Anderson MR, Anderson RC (2014) Longterm legacies and partial recovery of mycorrhizal communities after invasive plant removal. Biol Invasions 16:1979-1990. doi:10.1007/s10530-014-0642-0

Lau JA, Lennon JT (2012) Rapid responses of soil microorganisms improve plant fitness in novel environments. Proc Natl Acad Sci USA 109:14058-14062. doi:10.1073/pnas.1202319109

Lekberg Y, Koide RT, Rohr JR et al (2007) Role of niche restrictions and dispersal in the composition of arbuscular mycorrhizal fungal communities. J Ecol 95:95-105. doi:10.1111/j.1365-2745.2006.01193.x

Lenoir I, Fontaine J, Lounès-Hadj A (2016) Arbuscular mycorrhizal fungal responses to abiotic stresses: A review. Phytochem 123:4-15. doi:10.1016/j.phytochem.2016.01.002

Lin G, McCormack ML, Guo D (2015) Arbuscular mycorrhizal fungal effects on plant competition and community structure. J Ecol 103:1224-1232. doi:10.1111/1365-2745.12429

Lindner M, Maroschek M, Netherer S et al (2010) Climate change impacts, adaptive capacity, and vulnerability of European forest ecosystems. For Ecol Manag 259:698-709. doi:10.1016/j. foreco.2009.09.023

López-García Á, Azcón-Aguilar C, Barea JM (2014) The interactions between plant life form and fungal traits of arbuscular mycorrhizal fungi determine the symbiotic community. Oecologia 176:1075-1086. doi:10.1007/s00442-014-3091-7

Maček I, Dumbrell AJ, Nelson M et al (2011) Local adaptation to soil hypoxia determines the structure of an arbuscular mycorrhizal fungal community in roots from natural $\mathrm{CO}_{2}$ springs. Appl Environ Microbiol 77:4770-4777. doi:10.1128/AEM.00139-11

Mangan SA, Adler GH (2002) Seasonal dispersal of arbuscular mycorrhizal fungi by spiny rats in a neotropical forest. Oecologia 131:587-597. doi:10.1007/s00442-002-0907-7

Mantri N, Patade V, Penna S et al (eds) (2011) Abiotic stress responses in plants: present and future. Springer, New York, pp 1-19

Mariotte P, Meugnier C, Johnson D et al (2013) Arbuscular mycorrhizal fungi reduce the differences in competitiveness between dominant and subordinate plant species. Mycorrhiza 23:267277. doi: $10.1007 / \mathrm{s} 00572-012-0465-8$

Marler MJ, Zabinski CA, Callaway RM (1999) Mycorrhizae indirectly enhance competitive effects of an invasive forb on a native bunchgrass. Ecology 80:1180-1186. doi:10.1890/0012-9658(1999)080[1180:MIECEO]2.0.CO;2

Martinez-Garcia L, Manrique E, Pugnaire FI (2015) Different mycorrhizal fungal strains determine plant community response to nitrogen and water availability. J Plant Nutr 178:146-154 
Marulanda A, Porcel R, Barea JM, Azcón R (2007) Drought tolerance and antioxidant activities in lavender plants colonized by native drought-tolerant or drought-sensitive Glomus species. Microb Ecol 54:543-552. doi:10.1007/s00248-007-9237-y

Meier S, Azcón R, Cartes P et al (2011) Alleviation of Cu toxicity in Oenothera picensis by copper-adapted arbuscular mycorrhizal fungi and treated agrowaste residue. Appl Soil Ecol 48:117124. doi:10.1016/j.apsoil.2011.04.005

Meier S, Cornejo P, Cartes P et al (2015) Interactive effect between $\mathrm{Cu}$-adapted arbuscular mycorrhizal fungi and biotreated agrowaste residue to improve the nutritional status of Oenothera picensis growing in Cu-polluted soils. J Plant Nutr Soil Sci 178:126-135. doi:10.1002/jpln.201400092

Mena-Violante HG, Ocampo-Jiménez O, Dendooven L et al (2006) Arbuscular mycorrhizal fungi enhance fruit growth and quality of chile ancho (Capsicum annuum L. cv San Luis) plants exposed to drought. Mycorrhiza 16:261-267. doi:10.1007/ s00572-006-0043-z

Mendelsohn R, Dinar A (1999) Climate change, agriculture, and developing countries: does adaptation matter? World Bank Res Obs 14:277-293. doi:10.1093/wbro/14.2.277

Miransari M (2011) Hyperaccumulators, arbuscular mycorrhizal fungi and stress of heavy metals. Biotechnol Adv 29:645-653

Mohan JE, Cowden CC, Baas P et al (2014) Mycorrhizal fungi mediation of terrestrial ecosystem responses to global change: minireview. Fungal Ecol 10:3-19. doi:10.1016/j.funeco.2014.01.005

Monz CA, Hunt HW, Reeves FB, Elliott ET (1994) The response of mycorrhizal colonization to elevated $\mathrm{CO}_{2}$ and climate change in Pascopyrum smithii and Bouteloua gracilis. Plant Soil 165:7580. doi:10.1007/BF00009964

Morgan JA, LeCain DR, Pendall E et al (2011) $\mathrm{C}_{4}$ grasses prosper as carbon dioxide eliminates desiccation in warmed semi-arid grassland. Nature 476:202-205. doi:10.1038/nature10274

Morte A, Lovisolo C, Schubert A (2000) Effect of drought stress on growth and water relations of the mycorrhizal association Helianthemum almeriense-Terfezia claveryi. Mycorrhiza 10:115119. doi: $10.1007 / \mathrm{s} 005720000066$

Mummey DL, Rillig MC (2006) The invasive plant species Centaurea maculosa alters arbuscular mycorrhizal fungal communities in the field. Plant Soil 288:81-90. doi:10.1007/s11104-006-9091-6

Munkvold L, Kjøller R, Vestberg M et al (2004) High functional diversity within species of arbuscular mycorrhizal fungi. New Phytol 164:357-364. doi:10.1111/j.1469-8137.2004.01169.x

Munns R, Tester M (2008) Mechanisms of salinity tolerance. Annu Rev Plant Biol 59:651-681. doi:10.1146/annurev. arplant.59.032607.092911

Neuhauser C, Fargione JE (2004) A mutualism-parasitism continuum model and its application to plant-mycorrhizae interactions. Ecol Model 177:337-352. doi:10.1016/j. ecolmodel.2004.02.010

Neumann E, George E (2004) Colonisation with the arbuscular mycorrhizal fungus Glomus mosseae (Nicol. and Gerd.) enhanced phosphorus uptake from dry soil in Sorghum bicolor (L.). Plant Soil 261:245-255. doi:10.1023/B:PLSO.0000035573.94425.60

Neumann E, Schmid B, Römheld V, George E (2010) Extraradical development and contribution to plant performance of an arbuscular mycorrhizal symbiosis exposed to complete or partial rootzone drying. Mycorrhiza 20:13-23. doi:10.1007/ s00572-009-0259-9

Nielsen KB, Kjøller R, Bruun HH et al (2016) Colonization of new land by arbuscular mycorrhizal fungi. Fungal Ecol 20:22-29. doi:10.1016/j.funeco.2015.10.004

Nuñez MA, Horton TR, Simberloff D (2009) Lack of belowground mutualisms hinders Pinaceae invasions. Ecology 90:23522359. doi: $10.1890 / 08-2139.1$
Ocón A, Hampp R, Requena N (2007) Trehalose turnover during abiotic stress in arbuscular mycorrhizal fungi. New Phytol 174:879-891. doi:10.1111/j.1469-8137.2007.02048.x

Ohsowski BM, Zaitsoff PD, Öpik M, Hart MM (2014) Where the wild things are: looking for uncultured glomeromycota. New Phytol 204:171-179. doi:10.1111/nph.12894

Olsson PA, Tyler G (2004) Occurrence of non-mycorrhizal plant species in south Swedish rocky habitats is related to exchangeable soil phosphate. J Ecol 92:808-815. doi:10.1111/j.0022-0477.2004.00912.x

Orłowska E, Ryszka P, Jurkiewicz A, Turnau K (2005) Effectiveness of arbuscular mycorrhizal fungal (AMF) strains in colonisation of plants involved in phytostabilisation of zinc wastes. Geoderma 129:92-98

Ortas I (2012) The effect of mycorrhizal fungal inoculation on plant yield, nutrient uptake and inoculation effectiveness under longterm field conditions. Field Crop Res 125:35-48. doi:10.1016/j. fcr.2011.08.005

Pardo JM (2010) Biotechnology of water and salinity stress tolerance. Curr Opin Biotechnol 21:185-196

Pearson JN, Abbott LK, Jasper DA (1994) Phosphorus, soluble carbohydrates and the competition between two arbuscular mycorrhizal fungi colonizing subterranean clover. New Phytol 127:101106. doi:10.1111/j.1469-8137.1994.tb04263.x

Pellegrino E, Bedini S, Avio L et al (2011) Field inoculation effectiveness of native and exotic arbuscular mycorrhizal fungi in a Mediterranean agricultural soil. Soil Biol Biochem 43:367-376. doi:10.1016/j.soilbio.2010.11.002

Pellissier L, Pinto-Figueroa E, Niculita-Hirzel H et al (2013) Plant species distributions along environmental gradients: do belowground interactions with fungi matter? Front Plant Sci 4:500. doi:10.3389/fpls.2013.00500

Pendall E, Osanai Y, Williams AL, Hovenden MJ (2011) Soil carbon storage under simulated climate change is mediated by plant functional type. Glob Chang Biol 17:505-514

Porcel R, Ruiz-Lozano JM (2004) Arbuscular mycorrhizal influence on leaf water potential, solute accumulation, and oxidative stress in soybean plants subjected to drought stress. J Exp Bot 55:1743-1750. doi:10.1093/jxb/erh188

Porcel R, Aroca R, Cano C et al (2006) Identification of a gene from the arbuscular mycorrhizal fungus Glomus intraradices encoding for a 14-3-3 protein that is up-regulated by drought stress during the AM symbiosis. Microb Ecol 52:575-582. doi:10.1007/s00248-006-9015-2

Powell JR, Parrent JL, Hart MM et al (2009) Phylogenetic trait conservatism and the evolution of functional trade-offs in arbuscular mycorrhizal fungi. Proc Biol Sci 276:4237-4245. doi:10.1098/rspb.2009.1015

Prentis PJ, Wilson JRU, Dormontt EE et al (2008) Adaptive evolution in invasive species. Trends Plant Sci 13:288-294

Pringle A, Bever JD, Gardes M et al (2009) Mycorrhizal symbioses and plant invasions. Annu Rev Ecol Evol Syst 40:699-715. doi:10.1146/annurev.ecolsys.39.110707.173454

Querejeta JI, Allen MF, Caravaca F, Roldán A (2006) Differential modulation of host plant $\delta^{13} \mathrm{C}$ and $\delta^{18} \mathrm{O}$ by native and nonnative arbuscular mycorrhizal fungi in a semiarid environment. New Phytol 169:379-387. doi:10.1111/j.1469-8137.2005.01599.x

Räsänen K, Hendry AP (2008) Disentangling interactions between adaptive divergence and gene flow when ecology drives diversification. Ecol Lett 11:624-636

Rasmann S, Bauerle TL, Poveda K, Vannette R (2011) Predicting root defence against herbivores during succession. Funct Ecol 25:368-379. doi:10.1111/j.1365-2435.2010.01811.x

Rayner ADM, Coates D (1987) Regulation of mycelial organisation and responses. In: Rayner ADM, Brasier CM, Moore D (eds) 
Evolutionary biology of the fungi. Cambridge University Press, Cambridge, pp 115-136

Redecker D, Schüßler A, Stockinger H et al (2013) An evidencebased consensus for the classification of arbuscular mycorrhizal fungi (Glomeromycota). Mycorrhiza 23:515-531. doi:10.1007/ s00572-013-0486-y

Redman RS, Kim YO, Woodward CJDA et al (2011) Increased fitness of rice plants to abiotic stress via habitat adapted symbiosis: a strategy for mitigating impacts of climate change. PLoS ONE 6(7):e14823. doi:10.1371/journal.pone.0014823

Reinhart KO, Callaway RM (2006) Soil biota and invasive plants. New Phytol 170:445-457. doi:10.1111/j.1469-8137.2006.01715.x

Reininger V, Martinez-Garcia LB, Sanderson L, Antunes PM (2015) Composition of fungal soil communities varies with plant abundance and geographic origin. AoB Plants 7:plv110. doi:10.1093/aobpla/plv110

Richter BS, Stutz JC (2002) Mycorrhizal inoculation of big sacaton: implications for grassland restoration of abandoned agricultural fields. Restor Ecol 10:607-616. doi:10.1046/j.1526-100X.2002.01041.x

Roberts KJ, Anderson RC (2001) Effect of garlic mustard [Alliaria petiolata (beib. cavara and grande)] extracts on plants and arbuscular mycorrhizal (AM) fungi. Am Midl Nat 146:146-152

Rodriguez R, Redman R (2008) More than 400 million years of evolution and some plants still can't make it on their own: plant stress tolerance via fungal symbiosis. J Exp Bot 59:1109-1114. doi:10.1093/jxb/erm342

Rodriguez R, Woodward C, Redman RS (2010) Adaptation and survival of plants in high stress habitats via fungal endophyte conferred stress tolerance. In: Seckbach J, Grube M (eds) Symbioses and stress: joint ventures in biology. Springer, Dordrecht, pp 463-478

Sanders IR (2002) Ecology and evolution of multigenomic arbuscular mycorrhizal fungi. Am Nat 160(Suppl):S128-S141. doi:10.1086/342085

Scheirs J, De Bruyn L (2004) Excess of nutrients results in plant stress and decreased grass miner performance. Entomol Exp Appl 113:109-116. doi:10.1111/j.0013-8703.2004.00215.x

Scheublin TR, van Logtestijn RSP, Van der Heijden MGA (2007) Presence and identity of arbuscular mycorrhizal fungi influence competitive interactions between plant species. J Ecol 95:631638. doi:10.1111/j.1365-2745.2007.01244.x

Schützendübel A, Polle A (2002) Plant responses to abiotic stresses: heavy metal-induced oxidative stress and protection by mycorrhization. J Exp Bot 53:1351-1365. doi:10.1016/ S0981-9428(02)01411-0

Seguel A, Cumming JR, Klugh-Stewart K et al (2013) The role of arbuscular mycorrhizas in decreasing aluminium phytotoxicity in acidic soils: a review. Mycorrhiza 23:167-183

Shannon SM, Bauer JT, Anderson WE, Reynolds HL (2014) Plantsoil feedbacks between invasive shrubs and native forest understory species lead to shifts in the abundance of mycorrhizal fungi. Plant Soil 382:317-328

Smith SE, Read DJ (2008) Mycorrhizal symbiosis, 3rd edn. Academic Press, New York

Sochacki P, Ward JR, Cruzan MB (2013) Consequences of mycorrhizal colonization for Piriqueta morphotypes under drought stress. Int J Plant Sci 174:65-73. doi:10.1086/668224

Song F, Li J, Fan X et al (2016) Transcriptome analysis of Glomus mosseae/Medicago sativa mycorrhiza on atrazine stress. Sci Rep 6:20245. doi:10.1038/srep20245

Southworth D (ed) (2012) Biocomplexity of Plant-Fungal Interactions. Wiley-Blackwell, London

Staddon PL, Gregersen R, Jakobsen I (2004) The response of two Glomus mycorrhizal fungi and a fine endophyte to elevated atmospheric $\mathrm{CO}_{2}$, soil warming and drought. Glob Chang Biol 10:1909-1921. doi:10.1111/j.1365-2486.2004.00861.x

Stahl PD, Christensen M (1991) Population variation in the mycorrhizal fungus Glomus mosseae: breadth of environmental tolerance. Mycol Res 95:300-307. doi:10.1016/ S0953-7562(09)81238-0

Suchkova N, Darakas E, Ganoulis J (2010) Phytoremediation as a prospective method for rehabilitation of areas contaminated by long-term sewage sludge storage: a Ukrainian-Greek case study. Ecol Eng 36:373-378. doi:10.1016/j.ecoleng.2009.11.002

Sun XF, Su YY, Zhang Y et al (2013) Diversity of arbuscular mycorrhizal fungal spore communities and its relations to plants under increased temperature and precipitation in a natural grassland. Chin Sci Bull 58:4109-4119. doi:10.1007/s11434-013-5961-5

Treseder KK, Allen MF (2002) Direct nitrogen and phosphorus limitation of arbuscular mycorrhizal fungi: a model and field test. New Phytol 155:507-515. doi:10.1046/j.1469-8137.2002.00470.x

Urcelay C, Díaz S (2003) The mycorrhizal dependence of subordinates determines the effect of arbuscular mycorrhizal fungi on plant diversity. Ecol Lett 6:388-391

van der Heijden MGA, Boller T, Wiemken A et al (1998) Different arbuscular mycorrhizal fungal species are potential determinants of plant community structure. Ecology 79:2082-2091. doi:10.1890/0012-9658(1998)079[2082:DAMFSA]2.0.CO;2/ abstract

van Diepen LTA, Entwistle EM, Zak DR (2013) Chronic nitrogen deposition and the composition of active arbuscular mycorrhizal fungi. Appl Soil Ecol 72:62-68. doi:10.1016/j.apsoil.2013.05.012

van Velthuizen H, Huddleston B, Fischer G, et al (2007) Mapping biophysical factors that influence agricultural production and rural vulnerability. Environment and natural resources series no. 11. FAO, Rome, Italy

Varela-Cervero S, Vasar M, Davison J et al (2015) The composition of arbuscular mycorrhizal fungal communities differs among the roots, spores and extraradical mycelia associated with five Mediterranean plant species. Environ Microbiol 17:2882-2895

Vellend M (2010) Conceptual synthesis in community ecology. Q Rev Biol 85:183-206. doi:10.1086/652373

Verbruggen E, Kiers ET (2010) Evolutionary ecology of mycorrhizal functional diversity in agricultural systems. Evol Appl 3:547560. doi:10.1111/j.1752-4571.2010.00145.x

Vicente JR, Fernandes RF, Randin CF et al (2013) Will climate change drive alien invasive plants into areas of high protection value? An improved model-based regional assessment to prioritise the management of invasions. J Environ Manag 131:185195. doi:10.1016/j.jenvman.2013.09.032

Vogelsang KM, Bever JD (2009) Mycorrhizal densities decline in association with nonnative plants and contribute to plant invasion. Ecology 90:399-407. doi:10.1890/07-2144.1

Weis E, Berry JA (1988) Plants and high temperature stress. Symp Soc Exp Biol 42:329-346

Wyatt GAK, Toby Kiers E, Gardner A, West SA (2014) A biological market analysis of the plant-mycorrhizal symbiosis. Evolution (NY) 68:2603-2618. doi:10.1111/evo.12466

Yokota S, Ojima K (1995) Physiological-response of Root-Tip of Alfalfa low $\mathrm{pH}$ and aluminium stress in water culture. Plant Soil 171:163-165

Zabinski CA, Bunn RA (2014) Function of mycorrhizae in extreme environments. Soil Biol 41:201-214 Springer

Zheng C, Ji B, Zhang J et al (2015) Shading decreases plant carbon preferential allocation towards the most beneficial mycorrhizal mutualist. New Phytol 205:361-368. doi:10.1111/nph.13025

Zobel M, Öpik M (2014) Plant and arbuscular mycorrhizal fungal (AMF) communities-which drives which? J Veg Sci 25:11331140. doi:10.1111/jvs. 12191 